\title{
CONCISE
}

PUBLICATIONS

\section{Effects of Exogenous Estrogen and Progestin on Pituitary Responsiveness to Synthetic Luteinizing Hormone-Releasing Factor}

\author{
G. VANDenberg, G. DeVANe, and S. S. C. Yen \\ From the Department of Reproductive Medicine, School of Medicine, \\ University of California, San Diego, La Jolla, California 92037
}

A B S T R A C T The effect of estrogen and progestin on
pituitary responsiveness to $150 \mu \mathrm{g}$ synthetic luteinizing
hormone-releasing factor (LRF) was assessed in pre-
menopausal women receiving sequential $(n=12)$ and
combination ( $n=7$ ) contraceptive steroids. A marked
contrast in the time-course and maximal response to
LRF was found; a prompt but quantitatively smaller
luteinizing hormone ( $\mathrm{LH}$ ) response was seen during
cyclic combination therapy, while a delayed (five times)
but enhanced (fivefold) LH response was observed dur-
ing estrogen segments of cyclic sequential therapy. For
follicle-stimulating hormone (FSH), the maximum rise
was also higher, and the peak response was similarly
delayed in the latter group. The quantitative secretion
in response to LRF for LH (area under the curve), but
not for FSH, was significantly greater ( $P$ < 0.01 ) in
subjects receiving sequential, as compared to subjects
receiving combination treatment. In both groups, charac-
teristic gonadotropin responses to LRF were repro-
ducible and were independent of the duration of treat-
ment. Since LRF studies were performed during the
estrogen segment of treatment cycle in subjects receiving
sequential steroids, our data suggest that estrogen ex-

Dr. VandenBerg was a Research Fellow in Reproductive Endocrinology supported by a special fellowship grant from Rockefeller Foundation. Dr. DeVane is a Resident in Obstetrics and Gynecology. Work performed during an elective in Reproductive Endocrinology.

Received for publication 18 June 1973 and in revised form 4 February 1974. erts a direct feedback action at the pituitary level and that pituitary responsiveness to LRF is augmented by estrogen.

\section{INTRODUCTION}

Despite the widespread application of hormone contraception, the precise temporal relationship between the feedback action of synthetic contraceptive steroids and pituitary gonadotropin secretion has yet to be defined. Previously, Kastin, Schally, Gual, Midgley, Bowers, and Diaz-Infante and Kastin, Schally, Gual and Arimura have shown that pretreatment with combined estrogen and progestin (Lyndiol) did not prevent the release of luteinizing hormone $(\mathrm{LH})^{1}$ and follicle-stimulating hormone (FSH) in response to porcine luteinizing hormone-releasing factor (LRF) (1) and synthetic LRF (2). This finding has led to their conclusion that most of the action of these compounds in suppressing gonadotropin levels must occur at the hypothalamus or higher central nervous system (CNS) centers (3). However, effects of sequential contraceptive steroids were not evaluated. More recently, several lines of evidence which implicate a direct estrogen-pituitary feedback via modification of pituitary sensitivity to hypothalamic LRF (4-7) have come to light. To elucidate further this

${ }^{1}$ Abbreviations used in this paper: CNS, central nervous system; FSH, follicle-stimulating hormone; $\mathrm{LH}$, luteinizing hormone; LRF, luteinizing hormone-releasing factor. 
event, we studied effects of cyclic administration of estrogen and progestin, in the form of an oral contraceptive, on the pituitary responsiveness to synthetic LRF in premenopausal women.

\section{METHODS}

Gonadotropin responses to synthetic LRF were evaluated during 19 treatment cycles with synthetic estrogen and progestins in 16 premenopausal subjects. All had a history of regular menstrual cycles before treatment. The type of synthetic steroids and duration of medication are presented in Table I. LRF studies were performed during estrogen segments of the treatment cycle (days 7-16) in 10 subjects receiving sequential treatment and (days 9-20) in 5 subjects receiving combination treatment. Repeated studies were performed in three subjects (Table I).

Subjects were instructed to take the medication approximately 10-12 $\mathrm{h}$ before the study and were placed in bed in the ambulatory clinical research facility. Base-line blood samples were obtained at 15 -min intervals for $1-3 \mathrm{~h}$ via an indwelling venous catheter. At zero time, an i.v. bolus of synthetic LRF $(150 \mu \mathrm{g})$ was administered and was followed by 15 -min-interval blood sampling for $3 \mathrm{~h}$. For this study, the same batch of highly purified synthetic
LRF was prepared and utilized as previously described for human investigations $(4,6)$.

Quantitative comparison of LH-FSH release in response to LRF between the two groups was made by calculation of the area under the curve above the base-line levels during the first $3 \mathrm{~h}$ after LRF stimulation.

Serum $\mathrm{LH}$ and FSH concentrations were measured by specific radioimmunoassay and are expressed as $\mathrm{mIU} / \mathrm{ml}$ serum of second IRP-HMG $(8,9)$. Relative potency of the IRP and pituitary standard LER 907 was $38 \mathrm{mIU} / \mu \mathrm{g}$ for $\mathrm{FSH}$ and $210 \mathrm{mIU} / \mu \mathrm{g}$ for LH. All samples from a single study were measured in duplicate in the same assay.

The two-tailed Student's paired $t$ test was used for statistical analyses.

\section{RESULTS}

In subjects receiving combination estrogen and progestin treatment, LRF $(150 \mu \mathrm{g})$ induced a prompt increase in circulating $\mathrm{LH}$ and $\mathrm{FSH}$ with a time-course similar to that observed during the normal menstrual cycle (4). The mean peak concentration was reached at $30 \mathrm{~min}$ for $\mathrm{LH}(39.7 \pm 11.2 \mathrm{mIU} / \mathrm{ml})$ and at $60 \mathrm{~min}$ for FSH $(11.7 \pm 1.5 \mathrm{mIU} / \mathrm{ml}$ ) (Fig. 1). These incremental

TABLE I

The Duration, Type, and Study Schedule in Subjects Receiving Contraceptive Steroids

\begin{tabular}{|c|c|c|c|c|}
\hline \multirow[b]{2}{*}{$\begin{array}{l}\text { Subject } \\
\text { age)* }\end{array}$} & \multirow[b]{2}{*}{$\begin{array}{c}\text { Dura- } \\
\text { tion }\end{array}$} & \multirow[b]{2}{*}{$\begin{array}{c}\text { Study } \\
\text { day }\end{array}$} & \multicolumn{2}{|c|}{ Synthetic steroids } \\
\hline & & & Estrogen (dose) & Progestin (dose) \\
\hline & mo & & $\mu g$ & $m g$ \\
\hline \multicolumn{5}{|l|}{ Combination } \\
\hline G. T. & 12 & 9 & Ethinylestradiol (50) & Norgestrel $(0.5)$ \\
\hline J. $\mathrm{K}_{1} . \quad(24)$ & 38 & 9 & Ethinylestradiol (50) & Norgestrel $(0.5)$ \\
\hline J. K. (24) & 41 & 9 & Ethinylestradiol (50) & Norgestrel $(0.5)$ \\
\hline A. J. (26) & 20 & 12 & Mestranol (50) & Norethindrone (1.0) \\
\hline N. W. (25) & 7 & 17 & Mestranol (50) & Norethindrone (1.0) \\
\hline S. M. (20) & 30 & 20 & Mestranol (50) & Norethindrone (1.0) \\
\hline B. C. (24) & 24 & 20 & Ethinylestradiol (50) & Norgestrel $(0.5)$ \\
\hline
\end{tabular}

Sequentialł

$\begin{array}{lrrl}\text { B. C. (24) } & 1 & 14 & \text { Ethinylestradiol (100) } \\ \text { M. A. (29) } & 1 & 16 & \text { Ethinylestradiol (100) } \\ \text { M. A2. (29) } & 2 & 16 & \text { Ethinylestradiol (100) } \\ \text { N. C. (30) } & 3 & 11 & \text { Ethinylestradiol (100) } \\ \text { C. S. (23) } & 10 & 15 & \text { Ethinylestradiol (100) } \\ \text { F. K. (29) } & 54 & 7 & \text { Ethinylestradiol (100) } \\ \text { S. T. } \quad(22) & 25 & 11 & \text { Mestranol (80) } \\ \text { S. T . } \quad(22) & 27 & 11 & \text { Mestranol (80) } \\ \text { N. S. (20) } & 7 & 8 & \text { Mestranol (80) } \\ \text { D. V. (20) } & 4 & 13 & \text { Mestranol (80) } \\ \text { D. M. (19) } & 9 & 13 & \text { Mestranol (80) } \\ \text { P. T. (21) } & 12 & 12 & \text { Mestranol (80) }\end{array}$

Dimethisterone (2.5)

Dimethisterone (2.5)

Dimethisterone (2.5)

Dimethisterone (2.5)

Dimethisterone (2.5)

Dimethisterone (2.5)

Norethindrone (2.0)

Norethindrone (2.0)

Norethindrone (2.0)

Norethindrone (2.0)

Norethindrone $(2.0)$

Norethindrone (2.0)

* Combination regime is composed of estrogen plus progestin administered daily for 30 days in each cycle.

$\ddagger$ Sequential regime is composed of estrogen administration for the first 16 days followed by estrogen plus progestin combination for 5 days in each cycle. 

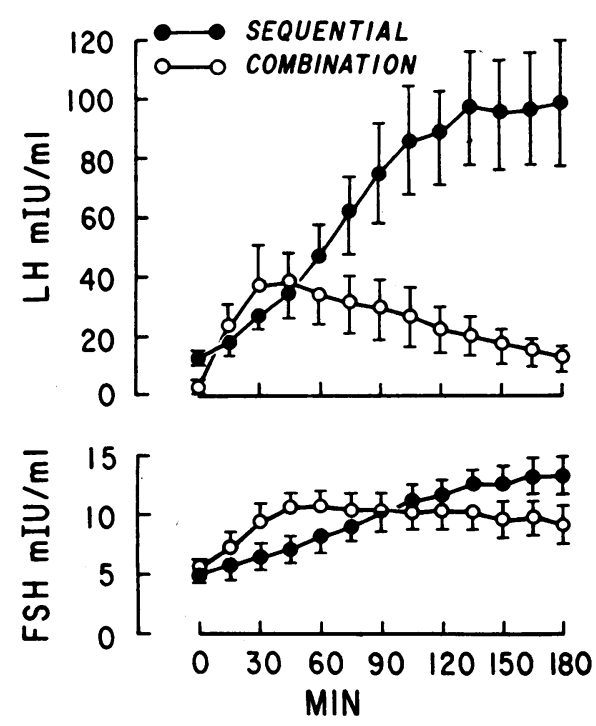

Figure 1 Contrasted patterns in the time-course and quantitative responses in serum FSH and $\mathrm{LH}$ to synthetic LRF $(150 \mu \mathrm{g})$ in subjects treated with combination $(n=7)$ and sequential estrogen-progestin $(n=12)$.

changes were similar to those seen during the early follicular phase but only to $30-50 \%$ of those observed during the luteal phase of the cycle (4). These diminished responses observed in subjects receiving combination estrogen and progestins need not be inconsistent with our finding of an enhanced LRF respose during the mid-luteal phase of the cycle (4), since the dose, duration, and the nature of steroids are distinctly different from each other.

In contrast, a delayed (135 vs. $30 \mathrm{~min}$ ) but enhanced peak (fivefold) with a sustained LH response to LRF was found in subjects receiving sequential estrogen and progestin (Fig. 1). When compared with the responses seen in subjects receiving combination treatment, the difference for $\mathrm{LH}$ was significant by $90 \mathrm{~min}$ after LRF $(P<0.005)$, and the maximum rise for $\mathrm{FSH}$ was also higher and similarly delayed, but statistically it was not significant (Fig. 1). The differences in the quantitative release and in the time-course between the two groups became more distinct when the data were analyzed as percent change from the control value (zero time). A diminished response for both $\mathrm{LH}$ and $\mathrm{FSH}$ within the first $60 \mathrm{~min}$ and a reversed event from $75-180 \mathrm{~min}$ was clearly shown in the sequential group as contrasted with the combination group (Fig. 2). These differences were significant for $\mathrm{LH}$ at $15-45(P<0.001), 60(P<0.01)$, and 135-180 $\mathrm{min}(P<0.2)$; and for FSH at 30-45 $(P<$ $0.01), 60(P<0.05), 150-165(P<0.02)$, and $180 \mathrm{~min}$ $(P<0.1)$. In both groups, characteristic gonadotropin responses to $L R F$ were reproducible in the same subjects (Fig. 3) and were independent of the duration of treat- ments (Table I). Within our experimental design, a similar qualitative feature was seen in subjects tested on $D_{1}$ or $D_{20}$ in the combination group and on $D_{7}$ or $D_{16}$ in the sequential group.

Fig. 4 shows the quantitative $\mathrm{LH}$ and $\mathrm{FSH}$ secretion above base line after LRF stimulation between the two groups. A significantly $(P<0.01)$ greater $\mathrm{LH}$ but not FSH secretion during the 3 -h period after LRF was found in subjects receiving sequential, as compared to the combination contraceptive steroid treatment.

\section{DISCUSSION}

Previously, Kastin et al. have shown that pretreatment with combined estrogen and progestin (Lyndiol) did not prevent the release of $\mathrm{LH}$ and $\mathrm{FSH}$ in response to porcine LRF (1) and synthetic LRF (2). This finding has led to their conclusion that most of the action of these compounds in suppressing gonadotropin levels must occur at the hypothalamus or higher CNS centers (3). However, effects of sequential contraceptive steroids were not evaluated. Our present study confirms their finding and has provided additional information which
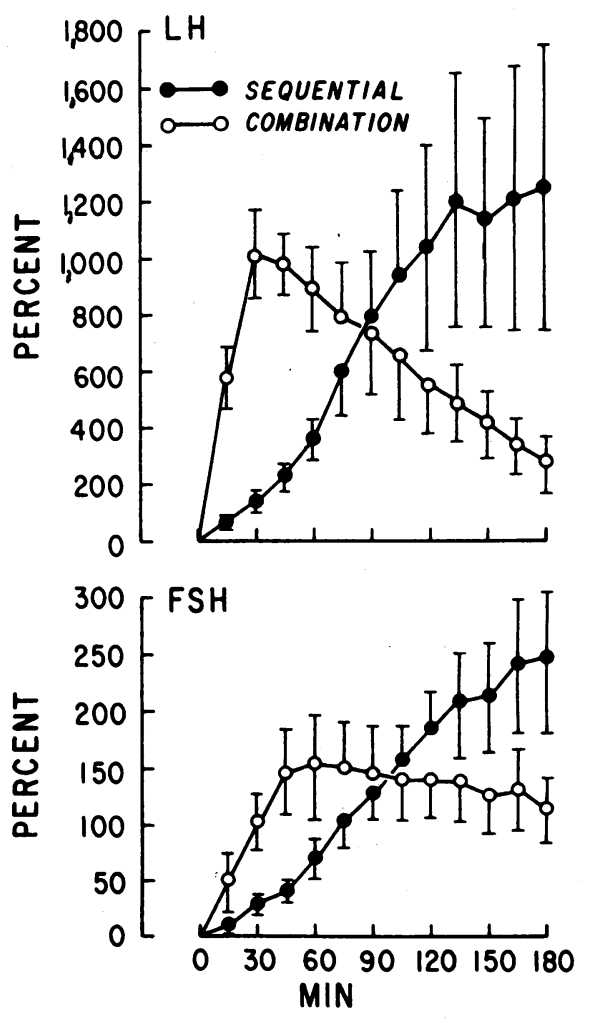

Figure 2 Contrasted patterns in the time course and percent increase from base line (at zero time) for $\mathrm{LH}$ and $\mathrm{FSH}$ in response to synthetic LRF $(150 \mu \mathrm{g})$ in subjects treated with combination $(n=7)$ and sequential estrogenprogestin $(n=12)$. 


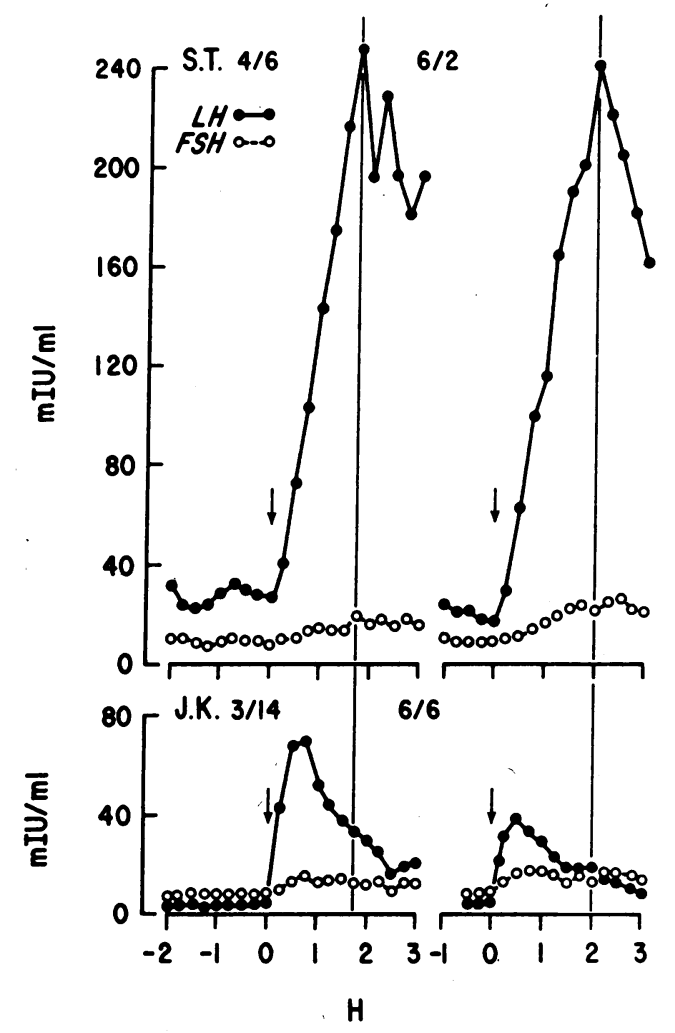

FIGURE 3 Comparison of the time-course and quantitative responses in serum $\mathrm{LH}$ and FSH concentrations to synthetic LRF during repetitive studies in the same subjects receiving sequential (S. T.) and combination (J. K.) cyclic estrogen-progestin treatments.

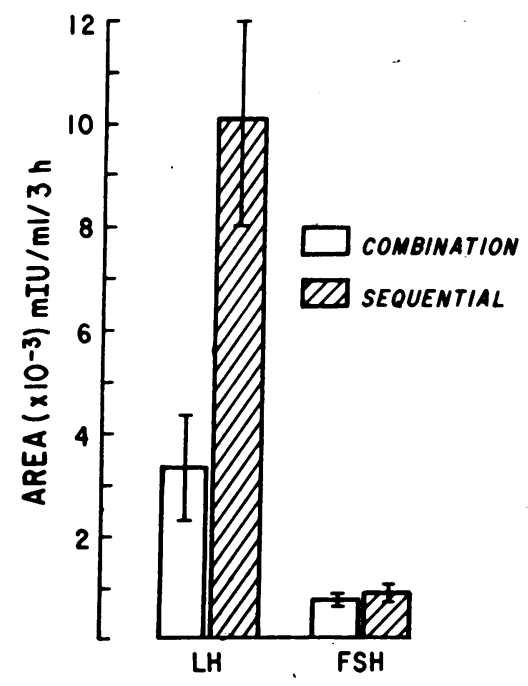

FigURE 4 Quantitative comparison of $\mathrm{LH}$ and FSH release in response to LRF between the two groups calculated by the area under the curve above the base-line levels during the first $3 \mathrm{~h}$ after LRF administration. suggests a direct feedback action of these steroids at the pituitary, as well as hypothalamic levels. Since the studies in the group receiving sequential therapy were obtained before the progestin was given in the cycle, our results then really reflect the effect of short-term pharmacologic effects of estrogens. The possibility of an added effect of progestin carry-over from a previous cycle should be considered, but it seems unlikely, since we have found a quantitative and qualitative similar event in postmenopausal subjects receiving estrogen - alone without progestin (7). Thus, our data indicate that in premenopausal women, cyclic treatment with synthetic estrogen in amounts contained in the sequential regimen modified pituitary responsiveness to exogenous LRF with an enhanced (fourfold) but delayed (five times) gonadotropin release.

The mechanism(s) by which estrogen exerts its infuence on pituitary gonadotrophs' sensitivity to LRF is not immediately apparent. Factors such as augmented gonadotropin synthesis, altered intrapituitary LRF metabolism, and the potentiation of LRF action on gonadotrophs by estrogen, either singly or in combination, having brought about the observed phenomenon should be considered. It is also plausible that a two-pool or compartment source of releasable pituitary gonadotropins, similar to that described for insulin (10), may exist and that pharmacological amounts of estrogen with relative constant circulating levels may suppress the acute releasable pool (first pool) and concomitantly enhance the slowly reactive system of gonadotropin release (chronic pool) within the population of pituitary gonadotropinproducing cells. The present finding supports the likelihood that an increased $\mathrm{LH}$ release in response to LRF from early to late follicular phase, observed in our earlier study, may be temporally related to a direct feedback action of estradiol on' the gonadotropic cell (4). The lack of impairment of the initial-phase gonadotropin response to LRF during the menstrual cycle and the appearance of the latent phase of gonadotropin release in cyclic estrogen-treated subjects could be explained by a difference in the time-course and levels of incremental changes between endogenous estradiol and sequential contraceptive steroid treatment. Although these data have provided information about the complex interaction between pituitary gonadotropin and ovarian steroids, the precise nature responsible for the observed relationship requires further investigation.

\section{ACKNOWLEDGMENTS}

The authors are grateful to Dr. R. Guillemin for the gift of synthetic LRF and for the excellent technical supervision by Dr. T. Siler and assistance by T. Vargo, J. Aurand, and P. Webster.

Antigens and antisera for the radioimmunoassay for $\mathrm{FSH}$ and LH were kindly supplied by the National Pituitary Agency and the National Institute of Arthritis and Meta- 
bolic Diseases. 2nd IRP-HMG was kindly supplied by the Medical Research Council, Mill Hill, London.

This work was supported by Rockefeller Foundation grant RF70029 and AID/csd/2785.

\section{REFERENCES}

1. Kastin, A. J., A. V. Schally, C. Gual, A. R. Midgley, Jr., C. Y. Bowers, and A. Diaz-Infante, Jr. 1969. Stimulation of $\mathrm{LH}$ release in men and women by LHreleasing hormone purified from porcine hypothalami. J. Clin. Endocrinol. Metab. 29: 1046-1050.

2. Kastin, A. J., A. V. Schally, C. Gual, and A. Arimura. 1972. Release of $\mathrm{LH}$ and FSH after administration of synthetic LH-releasing hormone. J. Clin. Endocrinol. Metab. 34: 753-756.

3. Kastin, A. J., C. Gual, and A. V. Schally. 1972. Clinical experience with hypothalamic releasing hormones. Part 2. Luteinizing hormone and other hypophysiotropic releasing hormones. Recent Prog. Horm. Res. 28: 201227.

4. Yen, S. S. C., G. VandenBerg, R. Rebar, and Y. Ehara. 1972. Variation of pituitary responsiveness to synthetic LRF during different phases of the menstrual cycle. J. Clin. Endocrinol. Metab. 35: 931-934.
5. Nillius, S. J., and L. Wide. 1972. Variation in LH and $\mathrm{FSH}$ responses to $\mathrm{LH}$-releasing hormone during the menstrual cycle. J. Obstet. Gynecol. Br. Commonw. 79: 861-873.

6. Siler, T. M., and S. S. C. Yen. 1973. Augmentated gonadotropin response to synthetic LRF in hypogonadal state. J. Clin. Endocrinol. Metab. 37: 491-494.

7. Yen, S. S. C., C. C. Tsai, G. VandenBerg, and T. Siler. 1974. Causal relationship between the hormone variables in the menstrual cycle. In Biorhythm in Reproduction. R. VandeWiele and F. Halberg, editors. John Wiley and Sons, Inc., New York. 219-240.

8. Yen, S. S. C., O. Llerena, B. Little, and O. H. Pearson. 1968. Disappearance rates of endogenous luteinizing hormone and chorionic gonadotropin in man. J. Clin. Endocrinol. Metab. 28: 1763-1767.

9. Yen, S. S. C., L. A. Llerena, O. H. Pearson, and A. S. Littell. 1970. Disappearance rates of endogenous follicle-stimulating hormone in serum following surgical hypophysectomy in man. J. Clin. Endocrinol. Metab. .30: 325-329.

10. Porte, D., Jr., and A. A. Pupo. 1969. Insulin responses to glucose: evidence for a two pool system in man. J. Clin. Invest. 48: 2309-2319. 